\title{
The definition of input parameters for modelling of energetic subsystems
}

\author{
M. PTACEK
}

Brno University of Technology, Faculty of Electrical Engineering and Communication

Department of Electrical Power Engineering - Technicka 3058/10, 61600 Brno, Czech Republic

\begin{abstract}
Summary. - This paper is a short review and a basic description of mathematical models of renewable energy sources which present individual investigated subsystems of a system created in Matlab/Simulink. It solves the physical and mathematical relationships of photovoltaic and wind energy sources that are often connected to the distribution networks. The fuel cell technology is much less connected to the distribution networks but it could be promising in the near future. Therefore, the paper informs about a new dynamic model of the low-temperature fuel cell subsystem, and the main input parameters are defined as well. Finally, the main evaluated and achieved graphic results for the suggested parameters and for all the individual subsystems mentioned above are shown.
\end{abstract}

\section{1. - Introduction}

The share of renewable energy sources in the European distribution and transmission networks significantly increases every year because a lot of countries provide financial benefits for energy produced by these sources. Moreover, it seems that installations of renewable sources can be useful for the environment. In anyway, the renewable power sources will be probably the only additional source of energy in the near future. Furthermore, many types of renewable sources are directly dependent on the atmospheric 
conditions at the place of their installation and therefore the produced power can be significantly variable. This fact conclusively shows that a good and reliable operation of the distribution networks has to be established because there are more possibilities of blackouts owing to sudden changes of the electric power.

This is a legitimate reason to simulate the distribution networks which contain renewable sources by mathematical models because they can be used for finding the behaviour and optimize the operations of the whole system. If the power of the whole system also depends on renewable energy sources, then it is appropriate to create mathematical models of these variable sources individually because each of these sources requires various input parameters for their simulations and exact results can be achieved [1].

\section{2. - The dynamic model of an energy system}

Creating a dynamic model of an energy system is a very complex and extended matter because it has to respect a lot of interconnections between many different disciplines, and the final dynamic model consists of many subsystems which represent individual components of the distribution networks (e.g. individual types of energy sources, lines, transformers, other electrical devices). Each used component in the model has to be described, simulated and evaluated separately. Although the subsystems need to work with large numbers of input and output data or parameters, the simulation of an individual subsystem does not have to be time-consuming. On the other hand, the system level simulation is very time-consuming because a lot of iteration calculations are used to find out the stable state of some part of the isolated distribution networks. This work is focused on the basic and simplified description of the fuel cell subsystem, the photovoltaic subsystem and the wind subsystem, respectively.

2'1. Fuel cell subsystem. - The fuel cell and the fuel cell subsystem present an electrochemical energy source or device that converts the chemical energy of the input flows of the reactants directly into electrical energy. A simplified description of the fuel cell general principle can be expressed by the chemical equations in [2].

A theoretical voltage of the fuel cell can be explained by Gibbs free energy. However, the voltage is lower than the theoretical voltage under real conditions [3] and this decrease can be calculated for a specific steady state of the fuel cell by Nernst equation [4]. Generally, Nernst equation brings the voltage of the fuel cell for constant values of temperature and partial pressures of the reactants:

$$
E_{N e r n s t}=E_{0}+\frac{\Delta S}{2 \cdot F}\left(T-T_{0}\right)+\frac{R \cdot T}{2 \cdot F} \cdot \ln \left(\frac{p_{\mathrm{H}_{2}} \cdot \sqrt{p_{\mathrm{O}_{2}}}}{p_{\mathrm{H}_{2} \mathrm{O}}}\right),
$$

where $E_{\text {Nernst }}$ is Nernst voltage (in V), $E_{0}$ is the voltage at standard conditions (in V), $\Delta S$ is the change of entropy (in $\mathrm{J} \mathrm{K}^{-1}$ ), $F$ is Faraday's constant (in $\mathrm{C} \mathrm{mol}^{-1}$ ), $T$ is the absolute temperature (in $\mathrm{K}$ ), $T_{0}$ is the standard temperature (in $\mathrm{K}$ ), $R$ is the universal gas constant (in $\mathrm{J} \mathrm{mol}^{-1} \mathrm{~K}^{-1}$ ), $p_{\mathrm{H}_{2}}$ is the hydrogen partial pressure (in atm), $p_{\mathrm{O}_{2}}$ is the oxygen partial pressure (in atm) and $p_{\mathrm{H}_{2} \mathrm{O}}$ is the water partial pressure (in atm). 
The real output voltage of the fuel cell stack expresses Nernst voltage that is decreased by overpotentials [5]. The mentioned overpotentials represent the voltage losses of the fuel cell stack and moreover the size of the losses influences the efficiency of the full cell stack significantly:

$$
V_{f c}=N_{0} \cdot\left(E_{N e r n s t}-V_{a c t}-V_{o h m}-V_{c o n}\right),
$$

where $V_{f c}$ is the output voltage (in V), $N_{0}$ is the number of series fuel cells in the stack, $V_{a c t}$ stands for activation losses (in $\mathrm{V}$ ), $V_{\text {ohm }}$ stands for ohmic (resistance) losses (in V) and $V_{\text {con }}$ stands for concentration losses (in $\mathrm{V}$ ).

It is necessary to point out that the dynamic behaviour of the fuel cell stack is good to know because then the development of the reactant flows or electric parameters can be determined. The dynamic behaviour can be simulated by differential equations of the partial pressure of the reactant gas $[2,4,6]$ :

$$
\frac{\mathrm{d} p_{\mathrm{H}_{2}}}{\mathrm{~d} t}=\frac{R \cdot T}{V_{a}}\left(q_{\mathrm{H}_{2}}^{\text {in }}-q_{\mathrm{H}_{2}}^{\text {out }}-q_{\mathrm{H}_{2}}^{r}\right)
$$

where $V_{a}$ is the volume of anode channel (in $\mathrm{m}^{3}$ ), $q_{\mathrm{H}_{2}}^{\text {in }}$ is the input flow of hydrogen (in mol s${ }^{-1}$ ), $q_{\mathrm{H}_{2}}^{\text {out }}$ is the output flow of hydrogen (in $\mathrm{mol} \mathrm{s}^{-1}$ ) and $q_{\mathrm{H}_{2}}^{r}$ is the hydrogen flow that reacts (in $\mathrm{mols}^{-1}$ ).

According to (3), the partial pressure is simply determined by Laplace transformation because the partial pressure of the reactant gas is linearly dependent on the flow of the reactant gas. Then the time constant is determined in the steady state of the fuel cell stack and it depends on the volume of the channel, the universal gas constant, the absolute temperature and the valve constant. The mathematical equations for other reactants (i.e. oxygen and water) can be expressed in a similar way.

Furthermore, the internal resistance is not constant and its change is considered in this work. The change of this resistance is expressed empirically and the development of the temperature is also solved by the empirical way in [7]. Therefore, the temperature change of the fuel cell stack is considered and it can be estimated according to $[2,8]$.

In table I [2] there are individual parameters that are used in the simulation of the dynamic behaviour of a fuel cell.

Some graphic results of the simulation are shown by figs. 1a and 1b [2]. Figure 1a [2] illustrates the dynamic changes of the voltage for different load currents. If load increases, then the voltage quickly drops and a voltage dip is generated at this instant. If load decreases, the situation is similar but a voltage swell is generated. In these situations the voltage gradually passes to a steady state but if the load current is short, the voltage does not achieve steady state. Figure 1b [2] brings important information about the behaviour of the power of the fuel cell stack in time and at different operational conditions, and shows the development of the power of the fuel cell stack at a different load current. Other important characteristics are available in [2]. 


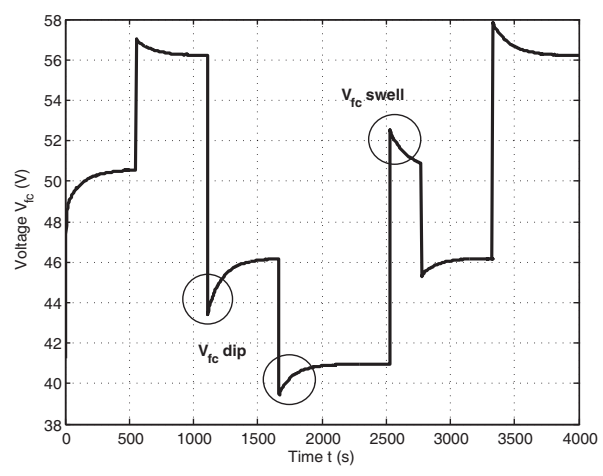

(a)

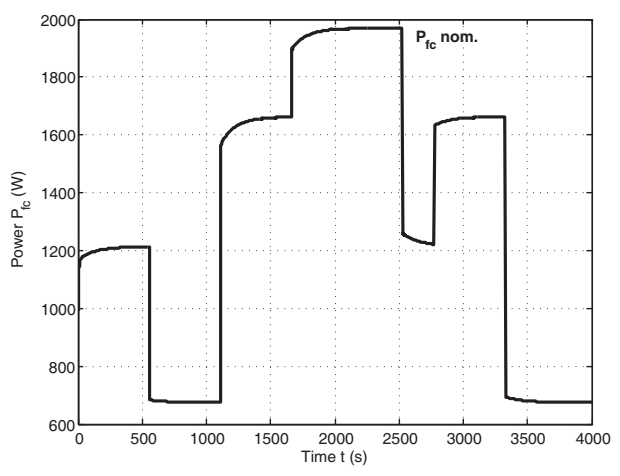

(b)

Fig. 1. - Curve of the voltage of the fuel cell stack (a) and curve of the power of the fuel cell stack at different load current (b) [2].

TABLE I. - Some parameters of the fuel cell subsystem [2].

\begin{tabular}{rccl}
\hline Nominal power & $P_{n}$ & 2 & $\mathrm{~kW}$ \\
Number of fuel cells in the series & $N_{0}$ & 80 & - \\
Voltage at standard conditions & $E_{0}$ & 1.229 & $\mathrm{~V}$ \\
Standard temperature & $T_{0}$ & 298.15 & $\mathrm{~K}$ \\
Hydrogen valve constant & $k_{\mathrm{H}_{2}}$ & $2.2 \cdot 10^{-5}$ & $\mathrm{kmol} \mathrm{atm}^{-1} \mathrm{~s}^{-1}$ \\
Hydrogen time constant & $\tau_{\mathrm{H}_{2}}$ & 2.46 & $\mathrm{~s}$ \\
Oxygen valve constant & $k_{\mathrm{O}_{2}}$ & $1.1 \cdot 10^{-5}$ & $\mathrm{kmol} \mathrm{atm}^{-1} \mathrm{~s}^{-1}$ \\
Oxygen time constant & $\tau_{\mathrm{O}_{2}}$ & 4.92 & $\mathrm{~s}$ \\
Water partial pressure & $p_{\mathrm{H}_{2} \mathrm{O}}$ & 1.0 & $\mathrm{~atm}$ \\
Utilization factor & $U$ & 0.8 & - \\
Hydrogen-oxygen flow ratio & $r_{\mathrm{H}-\mathrm{O}}$ & 1.168 & - \\
Ambient temperature & $T_{a}$ & 298.15 & $\mathrm{~K}$ \\
Heat capacity of the fuel cell stack & $C_{t}$ & 7000 & $\mathrm{~J} \mathrm{~K}$ \\
Thermal resistance & $R_{t}$ & 0.0195 & $\mathrm{~K} \mathrm{~W}^{-1}$ \\
\hline
\end{tabular}

2:2. Photovoltaic subsystem. - Solar cells represent basic devices which are able to generate electric power thanks to direct conversion of solar energy to electrical energy. Solar cells can be composed of semiconductors and each of them is conceived as a $p-n$ structure, respectively. Photovoltaic modules consist of solar cells and then a photovoltaic subsystem is created by a series-parallel combination of photovoltaic modules in order to obtain the required output voltage and current.

In table II [1] there are individual parameters which are used in the simulation of the photovoltaic subsystem.

Based on the equivalent mathematical circuit of the solar cell, consisting of a current source, a diode and two resistances, the relationship between the output voltage and the 
TABLE II. - Photovoltaic module parameters for simulation of its subsystem [1].

\begin{tabular}{rccc}
\hline Nominal array open-circuit voltage & $V_{\text {ocn }}$ & 36.9 & $\mathrm{~V}$ \\
Nominal short-circuit current & $I_{s c n}$ & 8.55 & $\mathrm{~A}$ \\
Number of photovoltaic cells in the series & $N_{s}$ & 60 & - \\
Series resistance & $R_{s}$ & 0.205 & $\Omega$ \\
Shunt resistance & $R_{s h}$ & 274.96 & $\Omega$ \\
Maximum power voltage & $V_{p m}$ & 29.8 & $\mathrm{~V}$ \\
Maximum power current & $I_{p m}$ & 7.89 & $\mathrm{~A}$ \\
Voltage-Temperature coefficient & $K_{V}$ & $-1.13 \cdot 10^{-1}$ & $\mathrm{~V} \mathrm{~K}^{-1}$ \\
Current-Temperature coefficient & $K_{I}$ & $5.13 \cdot 10^{-3}$ & $\mathrm{~A} \mathrm{~K}^{-1}$ \\
Diode ideality factor & $n$ & 1.3 & - \\
\hline
\end{tabular}

output current of the solar cell is defined as [1]

$$
I=I_{p h}-I_{0}\left[\exp \left(\frac{V+I \cdot R_{s}}{n \cdot V_{t}}\right)-1\right]-\frac{V+I \cdot R_{s}}{R_{s h}},
$$

where $I$ is the output current (in A), $I_{p h}$ is the photovoltaic current (in A), $I_{0}$ is the saturation current (in A), $V$ is the output voltage (in $\mathrm{V}$ ), $R_{s}$ is the series resistance (in $\Omega$ ), $n$ is the diode ideality factor, $V_{t}$ is the thermal voltage (in $\mathrm{V}$ ) and $R_{s h}$ is the shunt resistance (in $\Omega$ ). This equation has to be calculated and solved by the Newton-Raphson numerical method because the equation does not have a direct solution [1].

According to [2], the saturation current can be considered as

$$
I_{0}=I_{0 n}\left(\frac{T}{T_{n}}\right)^{\frac{3}{n}} \exp \left[\frac{e \cdot E_{g}}{n \cdot k}\left(\frac{1}{T_{n}}-\frac{1}{T}\right)\right],
$$

where $E_{g}$ is the bandgap energy of the semiconductor (in $\mathrm{eV}$ ). A more accurate value for $E_{g}$ can be achieved by respecting the given range of temperature of a module [9]. Other used dependences are available in [2].

Some results of the simulation are shown by figs. 2a and 2b [1]. Figure 2a [1] illustrates the validity of the proposed model because the $I-V$ curves of a practical module correspond with the simulated curves at different solar irradiance. A small error is generated for low irradiance, but the maximal difference between simulated and practical values of $V_{o c}$ is negligible. This validity of the proposed model is verified and confronted by electrical characteristics of the module at the standard test condition (i.e. $1000 \mathrm{~W} \mathrm{~m}^{-2}$, $25^{\circ} \mathrm{C}$, Air mass AM1.5). Furthermore, fig. 2b [1] shows the comparison of the power for an ideal and a real photovoltaic module. It also shows the huge and sudden changes of output power in short time and it informs that the subsystem is directly proportional to real solar irradiance. Other characteristics of validation of this subsystem are available in $[1]$. 


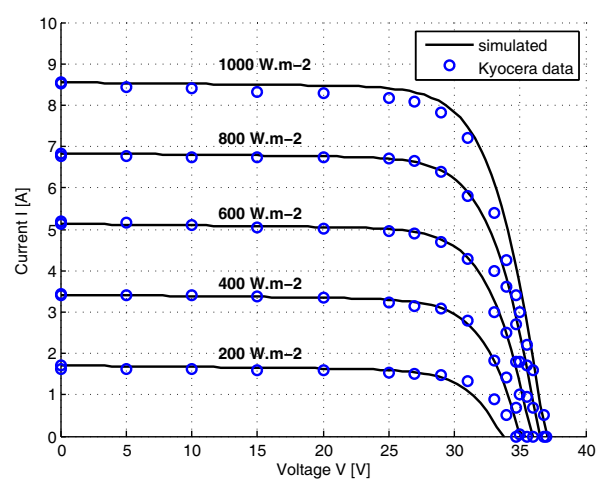

(a)

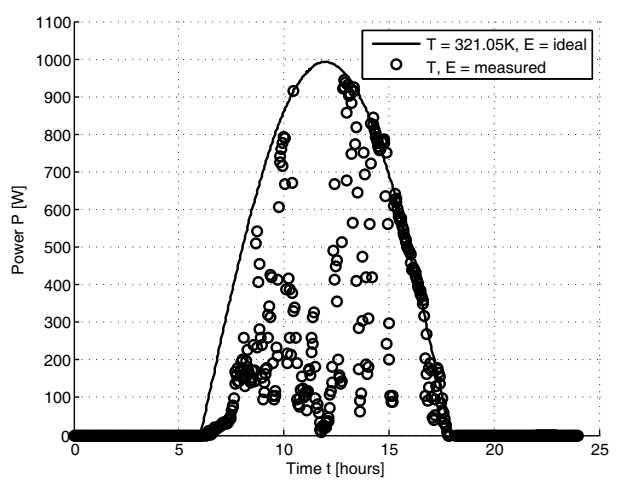

(b)

Fig. 2. - I- $V$ curves of a simulated and a practical photovoltaic module at different solar irradiance and $25{ }^{\circ} \mathrm{C}(\mathrm{a})$, and the comparison of output power of a simulated photovoltaic array $\left(N_{\text {par }}=2, N_{\text {ser }}=2\right)$ at ideal and real weather conditions (b) [1].

2:3. Wind subsystem. - Based on the principle of wind energy production, the wind subsystem represents a complex aerodynamic system. This is because the wind turbine rotor extracts energy from the wind and then this energy is converted into mechanical power and electrical power, respectively. Therefore, the aerodynamic, mechanical, electrical and control blocks are required for the wind subsystem modelling. The turbine model is represented by the mechanical power of the wind turbine extracted from the wind $[10]$ :

$$
P_{\text {rotor }}=\frac{1}{2} \cdot C_{P}(\lambda, \beta) \cdot \rho \cdot v_{\text {wind }}^{3} \cdot \pi \cdot R_{\text {rotor }}^{2},
$$

where $P_{\text {rotor }}$ is the power of the rotor (in W), $C_{P}$ is the power coefficient of the wind turbine, $\lambda$ is the tip speed ratio, $\beta$ is the pitch angle (in degrees), $\rho$ is the air density (in $\mathrm{kg} \mathrm{m}^{-3}$ ), $v_{\text {wind }}$ is the wind speed (in $\mathrm{m} \mathrm{s}^{-1}$ ) and $R_{\text {rotor }}$ is the rotor radius (in $\mathrm{m}$ ).

Generally, the density of dry air can be calculated by the ideal gas law. The value of the power coefficient is dependent on $\lambda$ (the ratio of the linear speed of the tip of the blades to the rotational speed of the wind turbine) [11] and $\beta$ (the angle of the turbine rotor) as well. Therefore, the power coefficient can be obtained by a non-linear function or by using a look-up table [12]. Moreover the power coefficient is a result of the rotor torque coefficient [10]. If the area swept by the blades of the wind power plant is known, then the power is $[10]$

$$
P_{\text {rotor }}=\frac{1}{2} \cdot C_{P}(\lambda, \beta) \cdot \rho \cdot v_{\text {wind }}^{3} \cdot A,
$$

where $A$ is the area swept by the blades (in $\mathrm{m}^{2}$ ). 


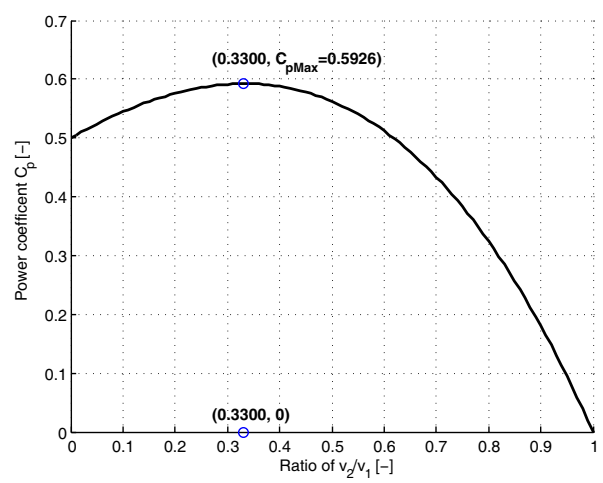

(a)

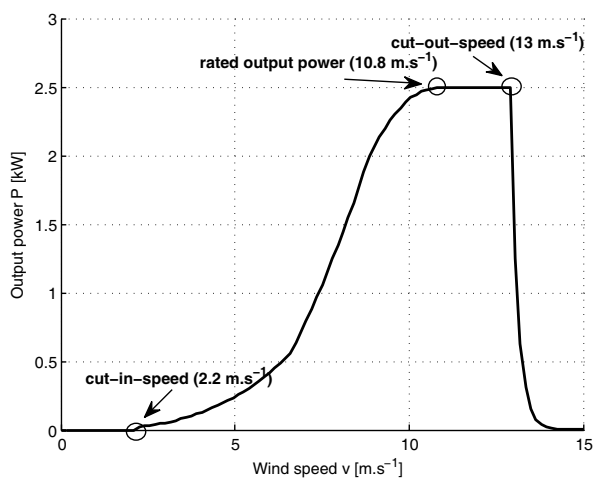

(b)

Fig. 3. - The power coefficient vs. the wind speed ratio (a) and power-wind curve of a wind power plant (b).

Figure 3a only demonstrates the power extractable from wind by the power coefficient (the maximum is called the Betz coefficient) for different wind speed ratios (the ratio of the speed behind the turbine $v_{2}$ and the speed in front of the turbine $v_{1}$ ). As mentioned above the real power coefficient is not dependent only on the wind speed and the wind speed ratio, respectively. Figure $3 \mathrm{~b}$ shows the mechanical power as a function of the wind speed at rated rotor speed and individual operating areas. These areas are important for the control of the wind turbine. One of them is bounded by the power-wind curve and its cut-in-speed limit $\left(2.2 \mathrm{~m} \mathrm{~s}^{-1}\right)$ and by the rated output power $\left(10.8 \mathrm{~m} \mathrm{~s}^{-1}\right)$ for the modelled wind turbine. The next one is limited by the rated output power and the cut-out-speed $\left(13.0 \mathrm{~m} \mathrm{~s}^{-1}\right)$.

\section{3. - Conclusions}

Generally, if the simulation respects the dynamic behaviour of renewable power sources, the design of these individual subsystems can be problematic because there are a lot of interrelations for each of these sources. Moreover the simulation of the distribution network is a very complex problem because iteration methods have to be used. The simulation itself can be time-consuming because a large number of input or output data for these individual subsystems have to be calculated. In addition, this time-consuming simulation is dependent on how much the individual subsystem is detailed and which output information is required.

This paper contains the results of research works funded from the project of the specific research program of Brno University of Technology No. FEKT-S-11-19/1446. The research was performed in the Center for Research and Utilization of Renewable Energy Sources. The author gratefully acknowledges financial support from the European Regional Development Fund under project No. CZ.1.05/2.1.00/01.0014. 


\section{REFERENCES}

[1] PtáčEK M. and MatoušEk A., Modelling of photovoltaic array for hybrid system, in Proceedings of the 12th International Scientific Conference on Electric Power Engineering 2011, Vol. 1 (VSB - Technical University of Ostrava, Ostrava, Czech Republic) 2011, pp. 1-4.

[2] Ptáček M. and MatoušEk A., New dynamic model of low-temperature fuel cell stack and the micro-cogeneration systems, in Proceedings of the 13th International Scientific Conference on Electric Power Engineering 2012, Vol. 1 (Brno University of Technology, Brno, Czech Republic) 2012, pp. 491-497.

[3] Gyu-Yeong C., Jong-Soo K., Hyun-Soo K., Byoung-Kuk L. and Won-Yong L., Proton exchange membrane fuel cell (pemfc) modeling for high efficiency fuel cell balance of plant (bop), in ICEMS, International Conference on Electrical Machines and Systems (IEEE) 2007, pp. 271-276.

[4] Papadopoulos P., Marinopoulos A. and Papagiannis G., Dynamic modelling of a grid-connected pem fuel cell in a distributed generation network, in PowerTech (IEEE, Bucharest) 2009, pp. 1-8.

[5] Yalcinoz T. and Alam M., Int. J. Hydrogen Energy, 33 (2008) 1932.

[6] Tesfahunegn S., Vie P., Undeland T. and Ulleberg e., A combined steady state and dynamic model of a proton exchange membrane fuel cell for use in dg system simulation, in IPEC 2010, International Power Electronics Conference (IEEE) 2010, pp. 2457-2464.

[7] Soltani M. and Bathaee S., A new dynamic model considering effects of temperature, pressure and internal resistance for pem fuel cell power modules, in DRPT 2008, Third International Conference on Electric Utility Deregulation and Restructuring and Power Technologies (IEEE) 2010, pp. 2757-2762.

[8] Khan M. and Iqbal M., Ren. Energy, 30 (2005) 421.

[9] Villalva M., Gazoli J. and Filho E., IEEE Trans. Power Electron., 24 (2009) 1198.

[10] Khan M. J. and Iqbal M. T., Dynamic modeling, simulation and control of a small wind energy conversion system, presented in ICME2003, Proceedings of the International Conference on Mechanical Engineering (Dhaka, Bangladesh) 2003.

[11] Borowy B. S. and Salameh Z. M., IEEE Trans. Energy Conver., 12 (1997) 73.

[12] El-Sattar A., Saad N. and Shams El-Dein M., Electr. Pow. Syst. Res., 78 (2008) 1240. 